\title{
Legal thinking and Countermeasures of environmental pollution in the course of Rural Urbanization
}

\author{
Guolin Zhang and Jianchen Sun \\ Jilin Agricultural Science and Technology University,Jilin Province, China \\ Jilin intermediate people's court ,Jilin Province, China \\ 491154210@qq.com; 356894743@qq.com
}

Keyword:Rural Urbanization; Environmental pollution; Law

\begin{abstract}
Rural environmental problems in the development of urbanization has become the focus of social concern. The water pollution, soil pollution, air pollution, solid waste pollution of rural environment has caused ecological crisis. Governance to rural environmental pollution is one of the key links of urbanization. Therefore, it is necessary to think of the law in the process of urbanization of rural environmental pollution problems.
\end{abstract}

\section{Introduction}

July 9, 2013,Premier Li Keqiang spoke again in Guangxi about promoting human-centered new urbanization. Urbanization is the engine and power of the development of China current and future, Urbanization has two core issues, First, the urbanization of land, Second, the urbanization of population, The urbanization of these two elements is having a profound effect on China economic and political and social. New urbanization emphasizes human centered .

According to statistics, China's urbanization rate of just over $52 \%$, If calculated by household registered population is about $35 \%$, Far below the average level of developed countries, nearly 80 percent. Gap is the potential. Looking to the future, Urbanization is the great engine of economic growth in China.With the development of urbanization, the environmental problems become increasingly prominent, has become the focus of attention of the whole society. The results of the environmental damage in rural areas not only harm the interests of farmers, but also directly related to the problem of feeding each one of us, On rural environmental pollution leads to be too numerous to enumerate the food safety accident[2].At present, China's rural environmental pollution, soil pollution, air pollution, solid waste pollution has caused the ecological crisis, All these can lead to disruption of agricultural production, reducing the quality of agricultural products and other issues. Therefore, we must attach great importance to rural environmental protection, actively carry out rural environmental pollution control work, Provide a good environment for China's agricultural development, This is the survival of our. Environmental problems in rural areas it is necessary to think of law[1].

\section{The Importance of the Rural Environment}

Impact on social life in rural environment. With the acceleration of urbanization, a growing number of rural and urban faced with the same types of pollution, While suffer pollution, but still provide the vegetables, eggs and milk and other food for the nearby city, This requires a lot of labor involved. City suburb village even became the main residence of the big city,Part of migrant workers work for city construction and life, a lot of gathered in the city suburbs; A number of city white-collar In order to alleviate the various aspects of pressure brought by rapid population growth in cities,also lived in the area near the city with convenient transportation, So the rural outskirts of the city not only has the characteristics of urban pollution,but also combines the characteristics of rural environmental pollution, If pollution incidents are not properly addressed, can easily generate social conflicts even cause social problems. 
Influence of rural environment for food safety. Food safety incidents occur frequently in recent years, attracted the attention of the whole society. Rural as a major producer of food shouldering the country's 13 million people drink food problem. The merits of the rural environment directly affects peoples health, life safety, more related to the healthy development of future generations, Therefore, the rural environment can not be ignored.In recent years, "poisonous rice" and water pollution incident after another, Pesticides in fruits and vegetables found excessive lead our exports experiencing problems so the phenomenon vividly, These facts are all in reminding us that attention to the rural environment, reduce environmental pollution in rural areas, that is, to protect ourselves, to protect our future generations[2,3].

\section{The Main Environmental Pollution in Rural}

In recent years, China's environmental pollution is getting worse, showing a trend that shift from industrial to agricultural, urban migration to rural. With the process of urbanization, the increasing importance of China's rural environment,rural environmental governance commitment to increasing, By summing found a wide variety of rural environmental pollution, complex structure, a very wide coverage.

Industrial wastewater and pesticide pollution. Environmental protection department as early as 2006 on statistics on the amount of chemical fertilizer and pesticide application, also conducted monitoring of organic pollution indicators, Although the application is large, and the indicators of normal, but fertilizer and pesticide pollution has an impact on water quality, and water reservoirs is indeed worrying. Water pollution in rural areas, not only affects the local residents, but also to make the water near the city were also affected. The extensive use of chemical fertilizers and pesticides over the years seriously polluted surface water, groundwater and coastal waters. Faced with increasingly complex environmental situation, rural water pollution, especially more and more pollution of drinking water sources in rural areas, and more serious consequences[4].

Pesticide residues and heavy metal contamination of soil. Environmental protection department in 2011 to monitor the pilot country 364 villages showed that soil samples exceeded the rate of $21.5 \%$ in rural areas, Garbage dumps surrounding ,farmland, vegetable and businesses surrounding soil pollution is heavy. All this indicates that the soil contamination has become one of the priorities of rural environmental pollution. The quality of the soil directly to the development of agriculture, rural construction, farmers' health have a critical impact.

Atmospheric dust pollution. In recent years, cities have to move out of some heavily polluted industries and enterprises, These companies will generate a lot of dust, but multiple alterations in the suburbs or rural areas around cities, undoubtedly brought enormous pressure to rural air quality. Rural did not achieve a comprehensive collective heating, Especially the winter of north is a major source of air pollution in rural areas,smoggy. China's rural straw burning phenomenon always more serious, in addition to affecting sight, blocking traffic, but also a serious impact on the atmospheric environment in rural areas. Automobile exhaust emissions of some affluent areas but also to add new sources of pollution in rural areas[5].

Solid waste pollution. Currently solid waste pollution in rural areas comes mainly from solid waste generated by the mining industry, plastic sheeting, garbage and human and animal feces. Garbage problem of rural residents for a long time, but so far have not established a comprehensive garbage recycling system, Because the rural population living scattered, almost no special garbage collection, transportation, disposal, treatment system, and even some rural no designated waste sites, also does not have perfect laws and regulations on the management and control, livestock and poultry manure is an important source, the accumulation of a large number of feces will produce odor, cause air pollution at the same time, also can cause the pollution of solid wastes, influence the surrounding environment. With the relocation of industrial enterprises to rural areas, which produces industrial waste has become an important source of rural solid waste pollution. 


\section{The Situation of China's Rural Environmental Legislation}

The legislative system of China's rural environmental law. Although the legal construction of China's environment has made considerable progress, but still a large gap with the developed countries, Due to the environmental pollution events in recent years continue to occur, the state has increased the environmental legislation and enforcement efforts, through understanding and continuous efforts, China has formed a relatively scientific and rational legal framework, have made certain achievements in the field of environmental law.

China's environmental legislation adopted in the "Environmental Protection Law" as the main mode of comprehensive legislation, the legislation of the rural environment into "Water Pollution Prevention Law," "Atmospheric Pollution Prevention Act" that applies across town, rural general provisions, and "Pesticide Management Regulations", "irrigation water quality standards," such specialized rural environment laws, regulations, standards, and so on.

Therefore, China is basically established a wide coverage, rich content, more perfect environmental legal system.tha in the guide of the "constitution","environmental protection law" as the main body, environmental protection law, administrative regulations, departmental rules and regulations, local regulations, rules of local governments, environmental standards, as well as other departments of environmental protection laws and the treaties.

Reflection on China's rural environmental legislative status. As the guiding ideas is backward our understanding of agriculture has been more conservative, But as the process of urbanization and the occurrence of a series of rural environmental pollution accident, the rural environment is more and more attention. Therefore, changing the previous misconceptions that industrial pollution hazards large, urban pollution is serious, and small agricultural pollution hazards, pollution is not serious in rural areas, to guide environmental legislation is necessary.

Rural environmental legislation is lack of independence, In our country for the rural environmental pollution control regulations, dispersed in different local regulations and not a complete law, While the "environmental protection law" also on this aspect relates to not much content, Therefore, has not formed the fundamental, integrity principle, system, measures and means of processing and other basic content, don't even say the comprehensive, systematic guidance and promote on the rural environmental pollution control. How effective coordination and smooth implementation becomes a more realistic problem. So we should establish a unified environmental pollution control in rural area of the law is the fix[6,7].

\section{The Legal Countermeasures of China's Rural Environmental Control}

To improve the rural environmental legislation. In view of the practical need of rural environmental protection laws and regulations, the author propose a specific rural environmental protection regulations, as China's existing legislation on environmental protection in rural areas the implementation regulations. This Ordinance may be for those special rural, the existing environmental legislation did not provide content to make a comprehensive, specific provisions, The current law has been related to the content, should according to the specific implementation issues in rural areas, to make corresponding regulations. When the time is ripe, then take this as an opportunity for the corresponding legal drafting or revising[8].

Strengthening the rural environmental law enforcement and supervision and inspection. First, improve the rural environmental supervision mechanism. China's rural township (town) most without the establishment of the environmental protection agency, foundation of environmental supervision is weak, resulting in the supervision, mode, means and effectiveness of passive. Therefore, must carry on the bold exploration and Practice on the mode of operation, mode, rural environmental protection into the planning of new socialist countryside construction, establish and improve the rural environmental protection office, equipped with a full-time staff and the establishment of environmental protection, environmental protection work contact, timely communication policy, feedback information. By strengthening the organization and management, to mobilize the enthusiasm of the cadres and the masses. 
Secondly, the environmental indicators into the official examination system, the establishment of the government at all levels of environmental protection "accountability", let the government departments at all levels to shoulder the responsibility for environmental protection.

Thirdly, the comprehensive use of legal means, administrative means and economic means, to improve the effectiveness of environmental law enforcement. The current environmental law to single administrative enforcement and direct control as the main means of law enforcement, is not suitable for the countryside more dispersed production and way of life, resulting in the rural environment law enforcement costs are high. Therefore, the use of legal means, administrative means at the same time, we should vigorously develop and use of economic instruments for environmental protection, strengthening policy guidance, Such as give preferential policies to the production and processing of green food and so on, Make the farmers to adopt environmentally friendly mode of production and life, thus greatly saving environmental law enforcement cost, improve the effectiveness of environmental law enforcement[9].

Finally, strengthen environmental enforcement and supervision by the masses, NPC and the CPPCC supervision, social supervision by public opinion combine enhanced environmental enforcement self-restraint.

To strengthen the judicial protection of the rural environment. First, the establishment of rural environmental protection circuit court. At present, China has 4 environmental court, on the basis of this, according to the characteristics of environmental problems in rural areas, rural environmental cases in special set up reception center of county court, the establishment of rural environmental protection circuit court, the rural environmental protection in criminal, civil, administrative cases and the implementation of "four in one"trial execution mode. According to the claims of the parties, grassroots, local trial including rural environmental pollution and damage aspects of the case. The trial and execution of unified rural environmental cases, can use its concentration effect, produce larger public influence, thus play a declaration and educational justice, concrete and vivid case can improve the environmental legal awareness of farmers; Secondly, the establishment of rural environmental litigation costs, reduce corrosion, free system, ensure that farmers could get the environmental lawsuit; To make the actual needs of our judicial system and the operation practice and environmental protection suit[10].

Although China has made some progress in the rural environment legislation, but is still insufficient compared with developed countries.Actively and effectively promote the legal construction of rural environmental pollution control, is the objective requirement of building a new socialist countryside, is the necessary measure to control environmental pollution in rural areas, is an important guarantee to promote the development of rural urbanization.

\section{References}

[1] H.H.Shao,D. wang: Anhui agriculture bulletin,Vol.22 (2016) No.14, p.27-29

[2] H.Zhao: Journal of henan university of finance and economics, Vol. 30(2015) No.04, p.136-142

[3] J.Lu:Environment construction in the process of rural urbanization (Ph.D.,Shanxi normal university,China2015),p32

[4] D.W.Ning:. Research on rural environment in the process of urbanization (Ph.D., Shandong agricultural university,Cina2015),p28

[5] A.F.Lu: Research on the legal issues of rural environmental protection in the process of urbanization (Ph.D., Hebei university,China2014),p35

[6] Y.X.Wang,M.H.Cui and Y.Fan: . Journal of changchun normal university,Vol. 32(2013) No.05, p.28-29

[7] Y.Shi: Research on the construction of new rural environmental protection legal system (Ph.D., Northeast forestry university,China2008),p42 
[8] Y.B.Niu,Q.Liu: Agricultural economy, (2017)No.03, p.40-42

[9] Y.Zhang: Research on rural environmental issues and governance paths in the context of new urbanization(Ph.D.,Anhui university China 2017),p51-54

[10] J.J.Zhai ,H.Li: Journal of xi 'an university of electronic science and technology,Vol. 25(2015) No.01, p.82-87 